\title{
O DIABO NÃO FOI CONVIDADO: CONTO FANTÁSTICO E TRADIÇÃO QUEBEQUENSE
}

Ana Luiza Ramazzina Ghirardi

\section{RESUMO}

Quando parte do Canadá ainda se chamava Nova França, a língua francesa encontrava entraves para se consolidar em sua forma escrita e, por isso, a literatura quebequense conheceu um nascimento tardio. Por aproximadamente um século, ela se confina quase totalmente à dimensão oral, conhecendo suas primeiras manifestações escritas apenas quando seu povo começa a resgatar da memória ancestral canções, contos e lendas. No século XIX, essa literatura escrita revela uma nova figura narrativa, a do contador. Este é um simples e fiel transcritor que adapta histórias criadas pela imaginação popular, ocorridas na França ou na colônia. Elas são objeto de crença popular e revelam o fantástico e o maravilhoso, descrevendo personagens quotidianos como símbolo de uma cultura que existe e que resiste. Este artigo se propõe a percorrer brevemente a história do Quebec e verificar como, inicialmente, prevaleceram as narrativas orais. Em seguida, mostra o desejo de um povo de estabelecer uma literatura escrita, literatura que irá resgatar histórias do universo oral. Como fio condutor, analisa-se o Conte Populaire de Charles Laberge sob a ótica de Propp (2010) e se sugere como essa mudança da literatura oral para a escrita impactou a criação de uma linguagem fantástica.

\section{PALAVRAS-CHAVE:}

Literatura quebequense; literatura fantástica; identidade; literatura oral

\section{O fantástico, a história: identidade cultural e a gênese dos contes fantastiques quebequenses}

O que nos leva a acreditar que no decorrer de uma festa o diabo possa chegar como um personagem não convidado? Como a narrativa literária nos leva por caminhos que nos conduzem por situações fantásticas que, normalmente, dificilmente nos convenceriam? Por meio de quais artifícios o texto nos seduz?

O leitor, apesar de se ver diante de uma situação aparentemente sem qualquer verossimilhança, encontra-se capturado por uma narrativa capaz de convencêlo de movimentos extraordinariamente fantásticos. Através de uma linguagem convincente, o leitor é surpreendido por estratégias discursivas que o levam a acreditar em diabos, cafeteiras que se transformam em damas, pés de múmias com vida própria, etc. Que efeitos são esses que nos conduzem ao universo fantástico? 


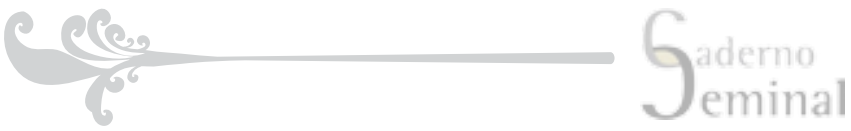

No Quebec, o mundo fantástico dá seus primeiros passos a partir de uma tradição oral que tem sua origem nos fatos históricos e na sua crença popular. As tradições francesas combinadas com o cenário do Novo Mundo e com o desejo de construir uma nova identidade mesclam-se para construir a base imaginativa sobre a qual se estruturam os contes fantastiques quebequenses, de sabor tão particular. Assim, para jogar um pouco de luz nesse universo, importa fazer um sobrevoo sobre as origens históricas desse povo e de seu desejo de narrar. De fato, pensar em contos fantásticos dentro da tradição quebequense, requer, primeiramente, relembrar um pouco da história do Canadá e sua ligação com a França na época da colonização. ${ }^{1}$

A história começa em 20 de abril de 1534 quando Jacques Cartier é incumbido por François I, rei da França, de explorar o Canadá e a região do rio Saint-Laurent. Ao chegar à praia de Gaspé, no golfo Saint-Laurent, Cartier finca uma cruz e reivindica a posse do continente para o rei cristão. Esse gesto que aproxima religião e território aponta, desde o princípio para uma conexão fundamental no imaginário do futuro povo do Quebec - como se verá em Conte Populaire.

Na França, o século XVI é um período de guerras entre católicos e protestantes. Ecos dessa importância crucial da religião (e da violência que se pode fazer em seu nome) chegam por certo ao Canadá que, no entanto, não oferecia naquele momento grandes atrativos à nação francesa. Durante um longo período, o Canadá fica esquecido pelos franceses e é preciso mais de cinquenta anos para que, em 3 de julho de 1608, o explorador francês Samuel de Champlain funde a cidade de Quebec. Ao criar a Nova França, Champlain tem como objetivo primeiro incentivar o comércio de peles. Significativamente, a iniciativa vem em conjunto com a intenção de colocar em prática a conversão dos indígenas. $\mathrm{O}$ encontro da tradição cristã e das lendas dos nativos iria constituir, posteriormente, o material de base para a construção do fantástico quebequense.

Quase quarenta anos depois, em 1642, é fundada a cidade de Montreal. A partir daí, os franceses procuram se instalar nesse território da América do Norte. A cidade de Quebec se desenvolve rapidamente até se tornar mais tarde a capital da Nova França; inicia-se, então, um período em que o interesse da França pelo Canadá se intensifica: os hábitos de vestuário do rei Louis XIV e de sua corte transformam em produto extremamente vailoso a pele de castor.

Em que pese este surto econômico, a população da Nova França em seu total continua pequena: em 1663, o Canadá abriga pouco mais de três mil habitantes permanentes. Muitas mulheres eram enviadas da França como "noivas" para equilibrar a distribuição de gêneros na colônia dominada exclusivamente por homens. A dança dos jovens contada em Conte Populaire ilustra bem as tensões e os medos das relações entre os gêneros. A vontade de aumentar

1 Os dados aqui apresentados têm como fonte Morton,D. Breve História do Canadá, São Paulo: Ed. AlfaOmega, 1989 


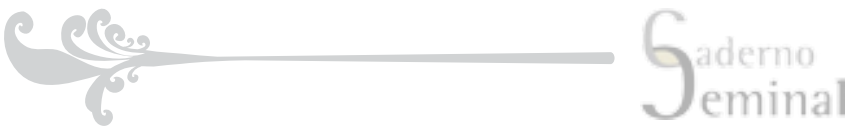

a população é grande porém, é preciso um século para que a Nova França consiga ampliar seu número de habitantes para sessenta mil.

Mas a lenta expansão demográfica não significa que o interesse por peles de castor não fosse ter efeitos importantes. Louis XIV concede o território da colonia a uma companhia, la Compagnie des Indes Occidentales, e reestrutura a administração sob os moldes das províncias francesas. A Nova França entra então em um período de expansão e seu território se estende gradualmente do Atlântico aos Grandes Lagos e da Baia de Hudson ao Golfo do México. Os franceses se mostram negociantes hábeis com os indígenas, mas Ihes falta uma marinha poderosa e "determinação para igualar o fluxo de milhares de imigrantes"2 que chegavam para as Treze Colônias vindos da Grã-Bretanha.

Guerras sucessivas entravam esse crescimento e, ainda em 1689, a Nova França conta apenas com 12.000 habitantes espalhados sobre um território imenso, comparativamente aos 250.000 das colônias inglesas. No momento em que se inicia a guerra da Conquista (1756-1763), as colonias inglesas são vinte vezes mais populosas que a colônia francesa. A sensação e solidão, dos amplos espaços vazios, compõem um pano de fundo sobre o qual a imaginação dos nativos das amplas planícies irá tecer histórias mesclando as tradições nativa e cristã.

Em 1760, um evento militar iria ser decisivo para a construção de uma identidade quebequense distinta daquela que se tornaria mais tarde canadense: a Inglaterra conquista militarmente a Nova França. Quebec é capturada e Montreal cercada por britânicos; as tropas francesas voltam para a metrópole. Após um século e meio de criação da Nova França, os franceses deixam a colônia para trás. Em 1763, o Tratado de Paris, coloca fim à guerra de Sete Anos e promove a reconciliação entre França, Grã-Bretanha e Espanha. A sobrevivência da cultura francesa depende agora desses imigrantes que, por sua vez, farão dela elemento decisivo para a construção de sua identidade.

Com a Conquista, inicia-se a presença inglesa no Quebec. Os administradores franceses voltam rapidamente para a França e a elite britânica se instala em seu lugar. O território que se chamava Canadá se torna a província de Quebec, o governador francês é substituído por um inglês e, com isso, as peles de castor começam a ser enviadas para o mercado inglês. Ainda como consequência do domínio inglês, a fé Católica é substituída pela Protestante. Mesmo com tudo isso, "os canadiens ${ }^{3}$ manteriam seu idioma, sua lei civil e suas instituições religiosas"4. O cenário é favorável aos ingleses. Após a independência dos Estados Unidos, numerosos Lealistas emigram para a América do Norte britânica e a proporção anglófona da população passa a aproximadamente 15\%.

Morton, 1989, p. 25

Colonos vindos da França ou seus descendentes.

Morton, 1989, p. 27 


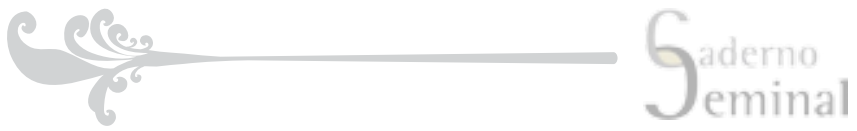

Em 10 de junho de 1791, o Ato $_{\text {constitucional}}{ }^{5}$ divide a colônia em duas províncias: O Baixo-Canadá (o Quebec, região oriental) para os canadenses franceses e o Alto-Canadá (o Ontario) para os colonos ingleses e lealistas ali desenvolverem uma sociedade britânica. As linhas de divisão entre culturas e histórias se estabelecem politicamente. Caberá aos canadiens construir uma narrativa que dê sentido à sua experiência frente ao perigo, sempre presente, de dominação pela cultura anglófona. Pode-se notar um progresso demográfico nessa nova civilização, em 1784 os habitantes passam a 110 mil e em 1812, a 330 mil. ${ }^{6}$ O Baixo-Canadá se angliciza. Em 1812, a maioria dos habitantes de Montreal fala inglês, assim como os moradores de Quebec.

\section{O nascimento da literatura quebequense}

\section{- Da literatura oral à escrita}

“(...) Longtemps après la Conquête de 1760, le français a continué d'être la langue des fourrures dans l'espace américain, et le rêve d'une Amérique française a poursuivi les esprits jusqu'à la fin du XIXe siècle, alimenté par l'exode des Québecois vers les États-Unis et la fécondité remarquable des Canadiens français." (Plourde, 2003, p. XXVII)

Após a Conquista inglesa de 1760, a quase totalidade da classe letrada volta para a França. Nesse momento, havia "um choque de línguas" na colônia: enquanto que a administração era de língua inglesa, a grande maioria da população era de língua francesa. Contudo, a distância era grande e os canadiens ficavam confinados aos modos da língua francesa conforme prevalentes em seu território, sem nenhuma ligação com a evolução da língua francesa na metrópole. Mas, semelhante ou diverso do francês metropolitano, o idioma se revela, a partir daqui, como fator absoluto de afirmação identitária. A literatura oral, traduzida por histórias contadas, ganha assim enorme importância: ela é o foco de resistência de uma cultura e de um modo de dizer.

"C'est dans le cadre de la nouvelle constitution de 1791 que la question linguistique se politise. [...] Les Canadiens défendent alors le français non parce qu'ils veulent en faire une langue hégémonique, mais parce qu'ils doivent résister aux pressions anglicisantes qui, elle, veut imposer la domination absolue de l'anglais. (Monière, Denis in Plourde, 2003, pp. 105-106) ${ }^{8}$

\footnotetext{
$5 \quad$ lei adotada pelo Parlamento britânico cujo principal objetivo era satisfazer os pedidos de lealistas que tinham deixado os Estados Unidos após a guerra da Independência americana - 1775-1783

$6 \quad$ Morton, 1989, p. 27

7 (...) Muito tempo depois da Conquista de 1760, o francês continuou a ser a língua das peles no espaço americano, e o sonho de uma América francesa perseguiu os espíritos até o fim do século XIX, alimentado pelo êxodo dos quebequenses em direção aos Estados Unidos e a fecundidade notável dos canadenses franceses." (Plourde, 2003, p. XXVII, tradução nossa)

8 "É no quadro da nova constituição de 1791 que a questão linguística se politiza. [...] Os canadenses defendem então o francês não porque eles querem fazer dele uma língua hegemônica, mas porque eles devem resistir às pressões anglicizantes que quer impor o domínio absoluto do inglês." (Monière, Denis in Plourde, 2003, pp. 105-106, tradução nossa)
} 
A língua francesa representará, então, um dos elementos que formará a nacionalidade canadense e seu uso, a cada dia mais ampliado na década de 1840-1850, acabará por se tornar o símbolo que unirá uma nação que se recusa a aceitar a assimilação. ${ }^{9}$ A ascensão da Inglaterra como potência, entretanto, e o declínio relativo do poderio francês fazem com que, a língua francesa perca seu caché político o que, no território americano, faz com que ela esteja sempre ameaçada de um desaparecimento total. A França, após a derrota para os britânicos, como já dissemos, desiste da colônia e cria uma distância entre sua nação e aquela canadense..$^{10}$

No que diz respeito especificamente à sua literatura escrita, quando o Canadá ainda se encontra sob o domínio de Louis XIV sob o nome de Nova França, encontramos um conjunto de textos da literatura quebequense compostos sob o Antigo Regime: são os chamados écrits coloniaux. Os escritos coloniais descrevem a gestão do país e representam, em si mesmos, sua literatura; são obras de exploradores, de colonos e de nativos do Canadá. Esses textos permitem descobrir as mais profundas raízes da identidade quebequense. São representantes desse período Jacques Cartier, Samuel de Champlain (os dois navegadores franceses que compõem escritos sobre suas expedições), Marie Morin (religiosa, escritos sobre a história de sua comunidade religiosa e as guerras iroquoises), Gabriel Sagard (sacerdote, escritos sobre os costumes dos Hurons e as aventuras de sua missão) e Jean Brébeuf (jesuíta, escrito sobre os ritos de morte dos Hurons). ${ }^{11}$ Como se pode notar, esses textos da primeira literatura gravitavam em torno da colonização e da religião e tinham um caráter utilitário e não ficcional.

Após essa primeiro período, encontramos um início de comunicação escrita veículada de pessoa a pessoa e constituída por pessoas anônimas que faziam a informação circular. Em 21 de junho de 1764, o primeiro jornal canadense bilíngue, La Gazette de Québec/The Quebec Gazette, é impresso no Quebec ${ }^{12}$; Montreal terá uma imprensa apenas quatorze anos depois. A importância da imprensa se mostra fundamental nesse período pois impulsiona a literatura de ficção a dar seus primeiros passos nos rumos daquela fusão de literatura antiga e contemporânea que se espalhava nos jornais da época (James Huston, Octave Crémazie, Philippe Aubert, entre outros). A literatura começa então a se diversificar e gêneros literários como o romance, o conto, a poesia e a crítica literária se desenvolvem. ${ }^{13}$

$9 \quad$ Noël, Danièle in Plourde, 2003, pp. 72-79

10 "La distance qui s'est opérée entre le français du Canada et celui de France par suite de l'interruption des échanges directs entre Canadiens et Fraçais, conséquence de la concession de la colonnie aux Britanniques, a été accentée par la Révolution française, qui a renouvelé l'expression des idées et provoqué, des changements linguistiques considérables. (Poirier, Claude in Plourde, 2003, p. 118)

11 Weinmann \& Chamberland, 1996

12 En 1764, la première imprimerie voit le jour à Québec. La nouvelle élite canadienne crée des sociétés littéraires, anime des journaux et favorise l'éclosion des premières oeuvres d'une littérature proprement canadienne. (Plourde, 2003, p. 57).

De la fondation du premier journal, La Gazette du Québec/ The Quebec Gazette, en juin 1764, jusqu'au tout début du XIXe siècle, la publication bilingue domine presque sans partage. Sur les neuf titres créés entre 1764 et 1804 , huit sont bilingues. Seule fait exception La Gazette littéraire, premier journal entièrement en français, lancé à Montréal par Fleury Mesplet em 1778. Elle ne survit qu'un an. (Plourde, 2003, p. 123)

$13 \quad$ Ibid, pp. 29-32 


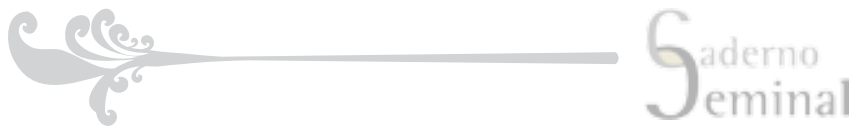

Antes da consolidação da imprensa, contudo, quando ainda não havia tipografia, o Canadá era fortemente dominado pelas tradições orais: lendas, contos, fábulas. A lenda, a princípio, tinha sua origem em narrativas religiosas, atos de santos que pudessem servir de exemplo aos fiéis. Com o tempo, elas perdem essa primeira conotação e guardam a ideia de maravilhoso. ${ }^{14}$ Philippe Aubert fils define assim a lenda da seguinte maneira: "Tentaria definir [a lenda] como sendo uma antiga tradição conservada pelos habitantes de um país." 15

Por essa razão, encontramos no gênero conto uma forma literária que ocupará um lugar central no século XIX quando a literatura escrita estava se consolidando ${ }^{16}$. Essa literatura se apresenta povoada pelo imaginário popular e mostra uma cultura canadense-francesa que surge de forma essencialmente oral. Lendas povoadas de bruxas, de duendes, de lobisomens (loups-garous), de almas perdidas e de diabos perpetuam uma moralidade no seio da qual o bem e o mal são claramente definidos. Verdadeiro imaginário coletivo do qual os contadores e escritores do século XIX buscaram sua fonte e que traduzirão através de um misto de conto, lenda e fábula que ajudará a consolidar a literatura quebequense.

\section{- Resgate da memória de um povo}

Para assegurar a sobrevida de sua cultura francesa, os Canadenses, instintivamente, começam a ressucitar da memória ancestral suas canções, seus contos e suas lendas e daí, fazer frutificar com uma rara energia esta herança que encontrou no Canadá sua terra de eleição. Essa literatura oral, patrimônio cultural transmitido boca à boca durante gerações é, de fato, a expressão mais fiel de matrizes culturais profundamente arraigadas na comunidade, trazendo para o texto escrito traços de um contador. A expressão literatura oral designa, em geral, exatamente esse conjunto de canções, contos e lendas, sem autores conhecidos durante algumas gerações.

Le genre est déterminé par la façon dont la communication s'établit entre le poète et son public. Le conte merveilleux et l'épopée sont des genres hérités, soumis à des conventions narratives liées à l'oralité. Le souvenir de l'énonciation orale s'inscrit dans l'image du conteur ou du récitant que le texte présente.

Les genres issus de la tradition orale, même lorsqu'ils s'incarnent dans des œuvres littéraires écrites et signées, gardent des traces stylistiques et énonciatives de leur situation de contact initiale entre le récitant physiquement présent et ses auditeurs. (Rullier-Theuret, 2006, p. 28) ${ }^{17}$

\footnotetext{
$\overline{14}$ "Dans son sens premier, le mot légende signifie donc 'ce qui est lu'. Or, en se libérant de son sens religieux, la légende se détache de ses liens avec l'écriture tout en gardant son caractère merveilleux." (ibid, p. 35)

15 "J'essaierai de définir [la légende] comme étant une ancienne tradition conservée par les habitants d'um pays". (ibid., p. 36)

16 Au cours de la décennie 1840, plusieurs écrivains s'emploient à relever le défi lancé par lord Durham qui a déclaré les Canadiens "peuple sans histoire et sans littérature. (Poirier, Claude in Plourde, 2003, p. 131)

17 "O gênero é determinado pelo modo como a comunicação se estabelece entre o poeta e seu público. O conto maravilhoso e a epopéia são gêneros herdados, submetidos a convenções narrativas ligadas à oralidade. A lembrança do enunciado oral se inscreve na imagem do contador ou do recitador que o texto apresenta.

Os gêneros saídos da tradição oral, mesmo quando se encarnam nas obras literárias escritas e assinadas, guardam traços estilísticos e enunciativos de sua situação de contato inicial entre o recitador fisicamente presente e seus ouvintes." (Rullier-Theuret, 2006, p. 28, tradução nossa)
} 
É a ligação cultural que une os pontos extremos da duração da história vivida e imaginada de um povo, isto é, o passado e o futuro, a geração anterior e a seguinte, o que há de contínuo e permanente na sucessão dos indivíduos. Costumeiramente, no universo da literatura oral, não há autores individuais mas uma produção coletiva. Essas narativas são veículo de aspirações, do imaginário coletivo por formar a identidade cultural através da língua eleita, no caso, a francesa. As lendas, os contos, as canções quebequenses de tradição oral falam de um povo orgulhoso, jovial, hospitaleiro, confiante, bon vivant e com espírito arisco de independência.

Pode-se notar a importância dessa literatura oral na dinâmica da cultura quebequense no momento em que os primeiros escritores surgem no século XIX e se mostram como que simples e fiéis transcritores dessas narrativas que as gerações transmitiam como parte de sua vida. Eles representam a narrativa de um fato real amplificado pela imaginação popular e que se tornou um objeto de crença, e revelam o fantástico e o maravilhoso que constituía a matéria-prima das histórias orais. É por isso que Malrieu (1992) afirma que "desde suas origens, o fantástico não parou de oscilar entre literatura formal e literatura popular". ${ }^{18}$ Com essa explosão de desejo de resgatar uma memória e vontade de consolidar uma língua através de sua literatura, pode-se contar mais de 20.000 contos orais na América francófona.

\section{- Conto fantástico ligado à tradição francesa e quebequense}

Os contadores desse período, como se disse, se contentavam em adaptar e em transcrever em língua escrita as lendas fantásticas. Essas versões escritas fixam de maneira definitiva histórias tanto vindas da França como nascidas em solo canadense, até então transmitidas unicamente boca à boca.

La frontière entre la légende et le conte, surtout le conte merveilleux, n'est pas précise. Luc Lacourcière, grand spécialiste québécois des traditions populaires, note que la plupart des contes du XIXe siècle sont des légendes: "L'on peut dire sans se tromper que le XIXe siècle nous a laissé beaucoup de légendes. Les premiers littérateurs canadiens se sont inspirés de la légende et ont rédigé des légendes qu'is ont appelées des contes." (Weinmann \& Chamberland, 1996, p. 38) ${ }^{19}$

Essas narrativas representam sempre uma visão particular do mundo, elas são a projeção fora de si das virtudes e dos poderes que os quebequenses queriam conquistar ou das fraquezas humanas e das angústias das quais eles desejavam se livrar. Elas são, a um tempo, memória da coletividade e fator de união entre seus membros. Elas constróem, e não apenas revelam, a identidade comum.

\footnotetext{
18 Depuis ses origines, le fantastique n'a cessé d'osciller entre littérature formelle et littérature populaire. (Malrieu, 1992, p. 35)

19 "A fronteira entre a lenda e o conto, sobretudo o conto maravilhoso, não é precisa. Luc Lacourcière, grande especialista quebequense das tradições populares, nota que a maior parte dos contos do século XIX são lendas: 'Pode-se dizer sem se enganar que o século XIX nos deixou muitas lendas. Os primeiros literatos canadenses se inspiraram na lenda e redigiram lendas que chamaram contos" (Weinmann \& Chamberland, 1996, p. 38, tradução nossa)
} 


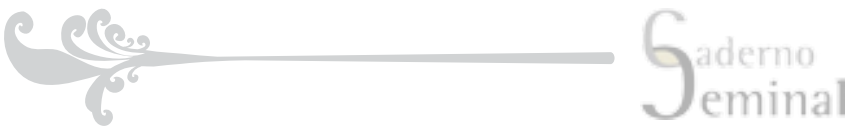

O conto representa uma narrativa de ficção em geral bem breve, transmitida oralmente. As ações, provas, peripécias são vividas por um ou mais personagens. Elas estabelecem uma distância entre o universo do conto e nosso mundo, a ficção e o real. Tempo e lugar são em geral indeterminados. No caso específico dos contos fantásticos, há uma profusão de elementos inverossímeis e personagens maniqueístas, mas ele permanece, em geral, como um gênero otimista, em que tudo sempre acaba bem. Os contos tradicionais são em grande número associados ao maravilhoso.

\section{Um conto quebequense: Conte Populaire - Charles Laberge}

Para ilustrarmos um pouco dessa história da literatura quebequense e da importante função que aí tem as narrativas orais com o imaginário de seu povo, apresentamos aqui um conto fantástico de Charles Laberge - cujo título, Conte Populaire, ${ }^{20}$ justamente indica tanto a sua origem oral (conto) e seu enraizamento na cultura (popular). Esse conto foi publicado no jornal Avenir²1, em fevereiro de 1848.

Ao analisarmos esse conto, a partir das reações e a natureza dos acontecimento, veremos que ele se revelará fantástico-maravilhoso. Segundo ressalta Todorov:

[...] no "maravilhoso os elementos sobrenaturais não provocam qualquer reação particular nem nas personagens, nem no leitor implícito. Não é uma atitude para os acontecimentos narrados que caracteriza o maravilhoso, mas a própria natureza desses acontecimentos". (Todorov, 2010, p. 60)

Nesse conto encontramos um esquema narrativo bastante comum; há três momentos chave que, segundo Propp (2010), caracterizam esse gênero: a situação inicial que, apesar de trazer elementos positivos, tranquilizadores, já apresenta também elementos negativos, perturbadores. O desenvolvimento da ação que se dá a partir de um elemento perturbador: aqui a chegada do diabo. O desenlace final, contudo, será - como de hábito - positivo: aqui, o cura consegue espantar o diabo e restabelece a ordem.

A dinâmica do texto apresenta uma narrativa veloz e com fatos surpreendentes, o que nos remete a um tipo de leitura que se promete breve - característica do gênero conto - e que confirma as expectativas iniciais do leitor ao começar o texto, como aponta Rullier-Theuret :

Ce ne sont pas les mêmes principes qui gouvernent les textes brefs et les textes longs, simplicité et complexité sont liées au nombre de pages. La brièveté prive le lecteur de détails et de développements, la rapidité de la narration et l'économie des moyens cherchent l'intensité des effets. (RullierTheuret, 2006, p. 11) $)^{22}$

\footnotetext{
$20 \quad$ O conto em sua íntegra encontra-se no final desse artigo.

21 Jornal publicado pela Fundação do Instituto canadense de Montreal a partir de 1847 (Plourde, 2003, p. 510)

22 "Não são os mesmos princípios que governam os textos breves e os textos longos, simplicidade e complexidade estão ligados ao número de páginas. A brevidade priva o leitor de detalhes e de desenvolvimentos, a rapidez da narrativa e a economia dos meios buscam a intensidade dos efeitos." (Rullier-Theuret, 2006, p. 11, tradução nossa)
} 


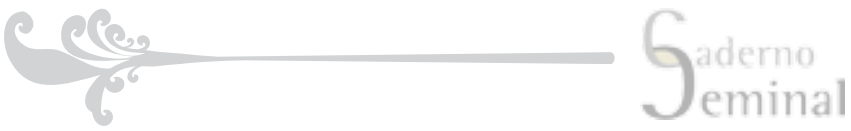

O enredo de Conte Populaire é exemplar dessa brevidade e simplicidade narrativas. Durante a festa, no início do conto, a sucessão de fatos se dá com tamanha velocidade que conduz rapidamente a narrativa para o elemento perturbador do conto.

\section{- A situação inicial: Terrebonne essencialmente francesa}

O conto apresenta uma narrativa em terceira pessoa; o narrador não representa um personagem que empreenderá alguma ação. Ele se apresenta, entretanto, como um contador que fará parte da história pois caberá a ele trazer informações importantes para o desenrolar da trama (a situação geográfica da casa, a importância da festa, por exemplo).

[...] les récits fantastiques à la troisième personne sont alors l'expression d'un je. [...] Le narrateur, qu'il s'identifie ou nom au personnage, est celui qui sait, ou tout au moins qui sait plus de choses que les autres. (Malrieu, 1992, pp. 135-136 $)^{23}$

Esse narrador/contador inicia sua narrativa fazendo uma comparação entre as cidades de Paris e Terrebonne. ${ }^{24}$ Já nesse primeiro momento, mesmo que de maneira rápida, o narrador remete o leitor para a cidade francesa retomando a ligação da história de Quebec com o país dos colonizadores. A cidade, cujo nome sugere o seu lado positivo (Terra Boa), surge como elemento introdutório ao conto através de sua característica jovial. A afirmação da identidade local a partir da identidade referencial francesa se dá com muita clareza embora seja fácil deixar de perceber esse ponto, uma vez que ele vem envolvido em relatos de maravilhas e espanto.

Também a descrição da pequena casa cuja localização se encontra em uma encruzilhada de quatro caminhos é cheia de significado. Essa circunstância se apresenta relevante pois o narrador nos explica que "é sempre ali que se faz esse assustador contrato: a venda da galinha preta"25. Os elementos populares, as crendices e medos que povoam a literatura oral encontram abrigo na forma escrita da ficção. Em seguida, o narrador evoca a festa tradicional francesa que se tornou importante no Canadá: la Sainte-Catherine ${ }^{26}$; o contexto histórico vem junto com a observação de que a festa é "tão antiga quanto a primeira cruz plantada sobre nosso solo", fazendo alusão a Jacques Cartier que, como já apontamos no início desse artigo, plantou uma cruz em solo canadense reivindicando a posse do continente para o rei francês François I.

\footnotetext{
23 "[...] as narrativas fantásticas na terceira pessoa são então uma expressão de um eu. [...] O narrador, que ele se identifique ou não com o personagem, é aquele que sabe, ou ao menos que sabe mais coisas que os outros." (Malrieu, 1992, pp. 135-136, tradução nossa)

24 Cidade do Quebec da periferia norte de Montreal, assim batizada em razão da fertilidade de suas terras terra boa (http://www.ville.terrebonne.qc.ca)

25 Sacrificando uma galinha preta à meia noite, em uma encruzilhada isolada, pode-se evocar o diabo para com ele fazer um pacto ( http://www.chouette-noire.com/sorcellerie/poulenoire.htm)

2625 de novembro, dia das catarinetes: todas as jovens de 25 anos que ainda não se casaram colocam um chapéu verde e amarelo e saem às ruas na esperança de encontrar um marido (Cretin, 1991, pp. 52-53)
} 


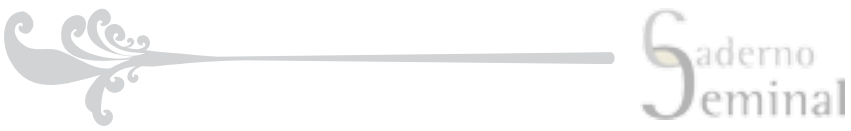

Aos poucos, esse narrador/contador vai montando uma teia de informações que compõem um esquema narrativo com dados que remetem à tradição francesa e é nessa lógica que ele conclui: "Terrebonne era então, como é ainda, essencialmente francesa". Ainda que a narrativa seja feita em terceira pessoa, como já dissemos, desde o início pode-se notar a importância do narrador/ contador que aparece como um personagem que fornece elementos que serão importantes para a continuação e a compreensão dos fatos que virão a seguir.

\section{- O desenvolvimento da ação: a tira e a música na festa}

Também reminiscente da narrativa oral é a forma como os primeiros personagens que compõem o conto são apresentados: "rapazes belos e altos com aparência de cavaleiros e jovens moças charmosas". O narrador, aqui, não apresenta um personagem individual, mas sim um grupo de jovens reunidos para a festa; esses personagens representam o pano de fundo da ação, mas nenhum deles se destacará, nem assumirá um papel importante para a continuação da ação, nenhum deles agirá de modo individual; todos jovens apresentam as mesmas ações: "cabeças que se agitavam, pés que sapateavam, sorrisos, olhares, palavrinhas ditas de forma negligente no ouvido de uma vizinha que passava, apertos de mão, beijos".

Cabe aqui o conceito de Propp sobre os atributos dos personagens e sua significação. Segundo o autor, os personagens da vida real se sobrepõem aos imaginários pois são mais "brilhantes, coloridos", já os personagens dos contos têm "influência da realidade histórica contemporânea, do epos dos povos vizinhos, e também da literatura e da religião, tantos dos dogmas cristãos como das crenças populares locais." (Propp, 2010, p. 85)

Na sequência do conto, em meio à toda a agitação, o clima de festa já estava instaurado e era causado pelo "fogo que ardia e a melaça obrigatória para as tiras $^{27}$ na Sainte-Catherine." E novamente a reação do grupo de jovens causada pelo forte odor do açúcar: "olhos brilhavam de alegria, (...) todos se atiravam sobre as tiras, arrancavam os pedaços de açúcar das mãos de seus vizinhos com gargalhadas loucas." O narrador/contador já nos anuncia que esse movimento trará alguma mutação: "todo o apartamento foi metamorfoseado em uma manufatura de tiras."

As tiras representam momento central da festa, por causa delas as pessoas brincam e a metamorfose se dá à medida que "cada um se permitia dourar o rosto de seu vizinho; todo mundo estava açucarado, sujo, tatuado, do modo mais pitoresco. Era um zunzum na casa que não se ouvia mais nada, uma balbúrdia ensurdecedora". Nessa passagem, o narrador/contador nos dá o tom do meio pelo qual uma transição vai se operando nos jovens convidados.

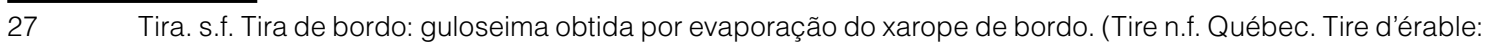
friandise obtenue par évaporation du sirop d'érable. - Le petit Larousse illustré, 2000) 


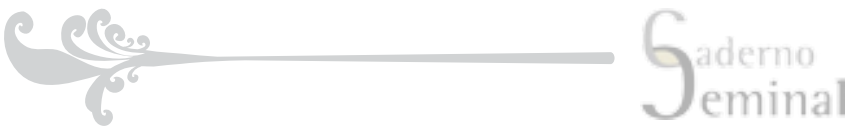

A festa apresenta elementos (o odor, a sensação dos convidados, o som, as ações frenéticas) que se tatuam nos convidados e os transformam tirando-os de seu cotidiano normal e conduzindo-os a um certo frenesi. A transição rápida do equilíbrio da situação inicial para a crise do desenvolvimento da ação se dá com a rapidez característica da oralidade, com a engenhosidade do contador de feira seduzindo seus ouvintes.

Nessa estratégia, um novo elemento é introduzido na narrativa e faz os convidados abandonarem a tira: a música. É preciso observar que, em um primeiro momento, o odor das tiras agita os jovens, em seguida, o som os transforma. O narrador/ contador nos dá várias pistas sobre o estado de espírito dos convidados que, ao ouvirem a música, "começam a cantarolar e a saltitar." Já metamorfoseados e tatuados pela tira, os convidados começam a dançar e "os sapatos e os coletes voavam de um lado ao outro: era um encantamento, um feitiço. (...) Os saltos, as cambalhotas, os vivas, as meia-voltas à direita e à esquerda, era um verdadeiro turbilhão (...) todas as danças animadas, vivas e alegres (foram tocadas). Todo mundo era transportado. Dançarinos e dançarinas, fora de si, saltavam, se chocavam, sapateavam a perder a cabeça." Ainda que nesse primeiro momento, tudo pareça evoluir normalmente, já encontramos alguns fatores quase imperceptíveis que começam a preparar espaço para o elemento perturbador da narrativa. O narrador/contador alerta que através da música os jovens passavam por um transe que os alucinava.

\section{- Elemento perturbador: situação negativa}

\footnotetext{
"No momento em que a dança estava mais animada, ouve-se subitamente, uma batida à porta: pa, pa, pa". A partir dessa batida, percebe-se que a narrativa é redirecionada; o bater à porta aparece como um recurso sonoro que acrescenta um novo elemento ao desenvolvimento da ação e o suspense é introduzido: "Um homem, vestido de preto dos pés à cabeça, figura bela e interessante, de aparência distinta, entra na casa". A cena nos reporta ao ensinamento de Propp:

O estudo dos atributos dos personagens inclui apenas as três rubricas fundamentais, que são as seguintes: aparência e nomenclatura, particularidade da entrada em cena e habitat. (Propp, 2010, p. 86)
}

O personagem que se apresenta à festa tem aparência "distinta" mas ainda não há uma nomenclatura definida para ele além da característica de sua vestimenta "de preto dos pés à cabeça"; entra em cena causando uma "certa surpresa" nas pessoas. Mesmo que essa inesperada visita tenha causado surpresa, o narrador/contador insiste no traço característico do povo canadense: os convidados o recebem "com a educação hospitaleira, particularidade nacional dos Canadenses". A dança recomeça e, a partir daí, o visitante é chamado pelo narrador/contador de étranger, termo que pode ter duas conotações, estrangeiro ou estranho. O visitante se surpreende com "a alegria franca, tão 


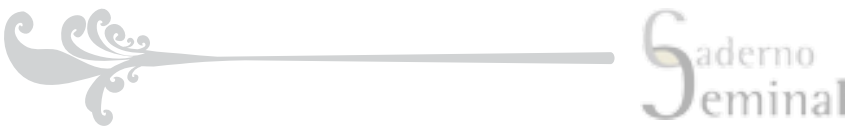

ingênua, tão expansiva" dos jovens. O étranger é convidado a dançar, e não só aceita, como escolhe a moça mais bonita e "a leva por toda parte ao som de um tambor."

Tem início aqui uma evolução do personagem na narrativa que culminará com a revelação de sua identidade. Malrieu indica que a lógica da narrativa fantástica se revela diferente daquela do cinema em relação aos efeitos que serão causados no leitor/expectador; enquanto no cinema há a necessidade de um efeito repentino que cause impacto no expectador, a narrativa fantástica apresenta uma evolução progressiva do personagem até o momento em que se revela o desconhecido. ${ }^{28}$

Assim, o início de um processo para essa revelação, nesse conto, se dá a partir de uma dança e do som de um tambor. O tambor, instrumento musical bastante popular, surge como um artifício desestabilizador para o conto. 0 banal e quotidiano se torna potencialmente ameaçador; é como se um ritual se preparasse: após esta cerimônia e um forte aperto de mão do seu partner a "dançarina solta um grito que faz estremecer todos os assistentes e desmaia". Importante aqui notar que sempre é um elemento ligado aos sentidos que redireciona o conto: olfato (a tira), audição (a música, o zunzum, o tambor), visão (a figura do homem de preto), o tato (forte aperto de mão). A relação do concreto, conhecido, com forças que nos transportam para dimensões ameaçadoras é carcaterístico do tecido das lendas populares e constitui fator determinante para o sucesso narrativo de Conte Populaire.

Importante também observar que, mesmo que o visitante tenha escolhido uma jovem para dançar, em nenhum momento a narrativa identifica esse personagem individualmente: ela é apenas uma bela dançarina jovem (no início do conto, o narrador já havia deixado claro que a festa era composta de belos jovens). A não individuação lembra o caráter geral das narrativas orais que, frequentemente, tinham uma intenção moralizante. É como se o narrador/contador dissesse: "Veja, isso pode acontecer com qualquer moça. É preciso ter cuidado".

Com a dança interrompida e a desconfiança causada pela situação estranha, as atenções voltam-se para o étranger. Os jovens, surpresos com o ocorrido, querem saber quem é esse homem singular. Voltando à perspectiva de Propp, encontramos aqui a esfera dos personagens que realizam funções: o homem de preto aparece como o personagem Antagonista (ou malfeitor) cuja esfera "compreende o dano, o combate e as outras formas de luta contra o herói, e a perseguição." (Propp, 2010, p. 77)

28 "Contrairement à ce qui se passe au cinéma, qui privilégie pour des raisons évidentes le phénomène et la recherche de l'effet que celui-ci peut provoquer, le récit fantastique se fonde principalement sur la révélation progressive par le personnage d'une réalité jusqu'alors inconnue." (Malrieu, 1992, p. 69) 


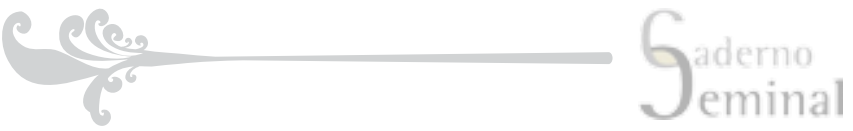

Diante da insitência da pergunta dos jovens sobre a identidade do personagem, vemos uma evolução nesse étranger que se mostra em um "mutismo e parecia pregado em seu lugar, sem nenhum movimento, apenas seus olhos se tornavam mais e mais brilhantes." Os jovens continuam a interrogá-lo e exigem que ele revele seu nome mas não há resposta. A cena se apresenta semeada de palavras que criam o clima para o desfecho do momento fantástico: jovens apavoradas / ansiedade / cena extraordinária / todos indecisos, quase terrificados / homem impassível que não se mexia./ Todos hesitam a casa treme.

O étranger continua imóvel, "apenas seus olhos se tornam mais e mais brilhantes e lançam raios; todos estão fascinados, ninguém consegue sustentar seu olhar de fogo." Os jovens tentam tirá-lo à força mas ele fica imóvel "como uma massa de chumbo." A ação vai evoluíndo de tal forma que cria a tensão para a conclusão da descoberta da identidade do homem de preto: "É o diabo! Grita com uma voz estridente o violinista. Todos repetem: é o diabo! Impossível descrever o pavor, a inquietação, a confusão" que são traduzidos por fugas, desmaios e gritos. A confusão envolve todos os moradores da cidade que despertam e se dão conta do insólito acontecimento. Quando alguns se acalmam, a decisão é unânime: procurar o cura da cidade. Ainda aqui, a simplicidade com que se aceita o maravilhoso - o diabo em pessoa vindo participar de uma festa aponta nitidamente para a dinâmica das narrativas orais populares.

Diante dessa revelação do diabo a todos os personagens do conto, podemos aqui fazer uma distinção notando que esse conto se apresenta dentro do conceito fantástico-maravilhoso. Segundo Malrieu, uma das maiores diferença entre a narrativa fantástica e o conto maravilhoso é a percepção do fenômeno pelos personagens:

Là [spécificité du personnage fantastique] réside l'une des plus importantes différences entre le récit fantastique et le conte merveilleux: le phénomène à l'œuvre dans le fantastique n'est pas plus ou moins étrange que celui des contes merveilleux : il n'est même pas nécessairement d'une nature différente ; en revanche, il n'est pas perçu par tous, pas de la même manière. [...] le personnage victime du phénomène n'est pas fondamentalement différent des autres : le diable, manifestement, peut apparaître à tous, et son intervention est vécue de la même manière par chacun. (Malrieu, 1992, p. 67) ${ }^{29}$

O diabo surge como elemento perturbador da ordem e é notado por todos os convidados, sua visão faz com que todos os personagens da festa reajam do mesmo modo. Em nenhum momento, a sua presença causará uma reação individual em qualquer personagem.

\footnotetext{
29 Aqui [a especificidade do personagem fantástico] reside uma das mais importantes diferenças entre a narrativa fantástica e o conto maravilhoso : o fenômeno em operação no fantástico não é mais ou menos estranho do que o dos contos maravilhosos : ele não é tão pouco necessariamente de uma natureza diferente ; em contrapartida, ele não é percebido por todos, não da mesma maneira. [...] o personagem vítima do fenômeno não é fundamentalmente diferente dos outros : o diabo, claramente, pode aparecer a todos, e sua intervenção é vivida da mesma maneira por cada um. » (Malrieu, 1992, p. 67, tradução nossa)
} 


\section{- Restabelecendo a ordem: situação final positiva}

Voltando a Propp e à esfera dos personagens, o cura realizará a função Auxiliar cuja ação compreende "o deslocamento do herói no espaço, a reparação do dano ou da carência, o salvamento durante a perseguição, a resolução de tarefas difíceis, a transfiguração do herói." (Propp, 2010, p. 77) Podemos dizer que esse personagem apresenta os três atributos levantados por Propp: aparência e nomenclatura: o cura está pálido e desfigurado; particularidade da entrada em cena: em pé, pálido e desfigurado e seu habitat : o presbitério. Após ouvir os fatos sucedidos, o cura toma a decisão de ir ao local mas antes mune-se de seu Petit-Albert, "o livrinho misterioso"30. Fica claro que o conto caminha para o restabelecimento da ordem transgredida pelo diabo e como esse conto não apresenta um herói individualizado, podemos dizer, como nos ensina Propp, que o auxiliar vai cumprir a função que seria específica do herói, ele vai "reparar o dano" (Propp, 2010, p. 81) causado pela visita do diabo.

A cena que vem a seguir e que restabelecerá a ordem é carregada de intensidade; ao se aproximar da casa, o cura pára e pede para as pessoas não se aproximarem. "Um clarão ofuscante" parecia espalhar pela casa um grande incêndio; o cura pode ver dentro da casa, "um homem de fogo sentado em uma cadeira sempre no mesmo lugar, imóvel."

Mesmo que o personagem auxiliar apareça como aquele que vai restabelecer a ordem, o narrador ainda diz que ele "supera o pavor que o dominava, abre o Petit-Albert e lê em voz alta algumas passagens..." Nada acontece então o cura recomeça, faz sinais misteriosos e diz em voz alta: "Em nome de Cristo, saia daqui!" A cena mistura religião e magia, o livro de bruxarias + a evocação de Cristo + os sinais misteriosos, juntos, conseguem desprender o diabo da cadeira.

A continuação mostra a violência que o narrador imprime às ações: a casa sacode violentamente, o solo treme, um turbilhão de fogo passa através de uma parede da casa, todos fogem gritando apavorados. Finalmente, para que o fato deixe uma marca concreta, o narrador diz que o diabo foge levando com ele uma parte da parede que nunca mais foi achada. Quanto ao cura, como se nada tivesse acontecido, volta tranquilamente ao presbitério com o Petit-Albert em baixo do braço.

\section{Conclusão:}

\section{A crença de um povo, a identidade quebequense e a literatura oral}

É importante ressaltar como o lado religioso mesclado pela crença popular e sua história dão o tom a esse conto. Isto importa porque significa mais um elemento que liga esse conto à tradição oral e às raízes do Quebec francês católico. Assim,

\footnotetext{
$30 \quad$ Livro de exorcismo contra bruxaria, inspirado pelos escritos de santo Alberto, o Grande; foi impresso pela primeira vez na França em 1668. (Wikipédia)
} 
como vimos, temos, a princípio, o motivo desencadeador que dará o pano de fundo ao conto: o encontro dos jovens para festejar Santa Catarina. Em seguida, o elemento perturbador: a chegada do diabo, personagem ligado à religião, o oposto de Deus que vem desestabilizar a ordem. Finalmente, o elemento que reestabelece a ordem, o cura com o seu Petit-Albert. Três momentos chave e decisivos do conto estão ligados à religião, à crença do povo quebequense. Mesmo que o diabo apareça como personagem fantástico-maravilhoso nesse conto, devemos ligá-lo também à crença de um povo em sua fé quando a literatura era apenas oral e essa história era contada e não escrita. O diabo que, nesse conto, representa um elemento perturbador da paz e que gera o ambiente fantástico-maravilhoso, era, no momento em que foi contado oralmente, parte da história desse povo e índice da relação estabelecida com a figura de um elemento cultural da fé cristã. Bozzetto e Huftier ressaltam que até o século XVII, esse tipo de aparição não perturbava a ordem e era aceita sem ligação a um fenômeno fantástico e sim como um elemento racional, ligado à religião. ${ }^{31}$

O que faz a o universo literário fascinante é a possibilidade de múltiplas leituras que nos oferece. Não há o modo certo de ler mas sim a descoberta da narrativa aos olhos do leitor. Um conto fantástico-maravilhoso pode permitir uma enorme gama de interpretações. O conto de Charles Laberge pode ser lido apenas como uma história de uma festa em que o diabo chega inesperadamente e cria uma grande confusão. Mas também pode oferecer muitos caminhos a serem explorados revelando uma história fantástica-maravilhosa enraízada em uma tradição secular. O que nos dispusemos a fazer nessa breve análise, foi encontrar uma entre tantas possibilidades apontando a figura do diabo - com sua dimensão cultural tão arraigada e tão antiga - estabelecendo o elo que reforça a ideia do conto oral como elemento de consolidação e resistência cultural.

O Conte Populaire veio não só do folclore e da tradição quebequense mas também da tradição francesa através da devoção à Santa Catarina e da crença no Petit-Albert. Essas duas tradições se fundem e encontram a sua consolidação através da escrita de autores como Charles Laberge, nesse sentido emblemático do tipo de escrita que marca o Canadá do século XIX. A relação entre imaginário popular e narrativa fantástica aparece também na literatura francesa - como, por exemplo, em Nodier - mas, no Quebec, ela faz parte de um movimento de afirmação nacional tão complexo quanto fascinante.

31 Jusque-là [XVIle siècle), l'apparition de saints, de fantômes, la présence du diable etc., cela ne violait en rien un ordre, et donc était accepté sans que surgisse um sentiment de trouble fantastique, mais simplement de la peur ou de l'émerveillement, car la religion le rendait acceptable pour la raison. (Bozzetto \& Huftier, 2004) 


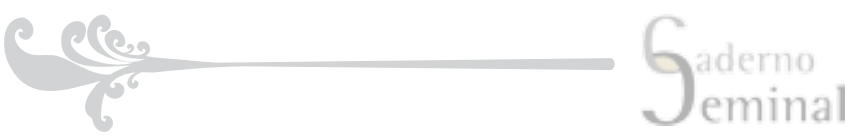

\title{
THE DEVIL WAS NOT INVITED : CONTES FANTASTIQUES AND QUEBECOIS TRADITION
}

\begin{abstract}
Written forms of French took a long time to consolidate in Canada during the period when part of the country was still la Nouvelle France. This entailed a corresponding relative delay in the emergence of the first Quebecoise literature. For around one century after the early occupation of the land, literature in Canada remained mostly oral. The first written texts would be marked by attempts to retrieve ancestral folk stories, legends and songs. In the $19^{\text {th }}$ century, these texts introduced the character of the narrator/story teller who functioned as the living memory of stories coming from the time of the early settlers. Such stories, which may be told as having taken place either in France or in Canada and bring to the fore folk traditions, are full of fantastical and gothic elements and function as a piece of cultural identity and resistance for Quebec. This paper analyses one such text, the Conte Populaire from the theoretical perspective offered by Propp (2010) by pointing its connections with the story of Quebec, which is briefly presented here, and with its social function within Quebec society.
\end{abstract}

\section{KEY WORDS:}

Quebec literature; contes fantastiques; cultural identity; oral literature

\section{REFERÊNCIAS}

BOZZETTO, R. \& HUFTIER, A. Les frontières du fantastique - approches de l'impensable em littérature. France, Presses Universitaires Valenciennes, 2004

CRETIN, N. \& THIBAULT, D. Le livre des fêtes. Italie: Gallimard, 1991

MALRIEU, Joël. Le fantastique. Paris: Hachette, 1992

MORTON, Desmond. Breve História do Canadá. São Paulo: Ed. Alfa-Omega, 1989

PLOURDE, Michel (direction). Le français au Québec: 400 ans d'histoire et de vie. Québec: FIDES, 2003

PROPP, Vladimir I. Morfologia do Conto Maravilhoso. Rio de Janeiro : Editora Forense Universitária, 2010

RULLIER-THERET, Françoise. Les genres narratifs. Paris: Ellipses Éditions, 2006 


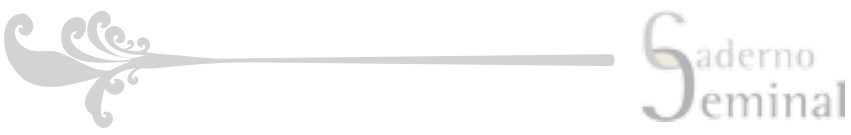

TODOROV, Tzvetan. Introdução à literatura fantástica. São Paulo: Perspectiva, 2010

WEINMANN, H. \& CHAMBERLAND, R. (direction). Littérature québécoise: des origines à nos jours. Montreal: Éditions Hurtubise, 1996

\section{Sites consultados:}

http://www.chouette-noire.com/sorcellerie/poulenoire.htm

http://grandquebec.com/legendes-du-quebec/contes-du-quebec/

\section{Anexo:}

\section{Conte Populaire - Charles Laberge (1827-1874) ${ }^{32}$}

Ce conte est une représentation typique des contes populaires de l'époque, avec des personnages également typiques.

Paris ne s'est pas fait en un jour, Terrebonne non plus. Or, donc, Terrebonne qui est aujourd'hui un beau et grand village, étendu de tout son long sur la côte de la rivière Jésus, n'était, au dernier siècle, qu'un tout petit enfant qui s'essayait en jouant à grimper sur la côte. Il y avait dans ce petit village une petite maison, dont l'emplacement se trouve aujourd'hui au pied de la côte, au beau milieu de Terrebonne. Cette maison se trouvait à la fourche de quatre chemins, circonstance importante quand on sait que c'est toujours là que se fait cet effrayant contrat : la vente de la poule noire. Le ciel était beau mais la terre bien triste. L'automne l'avait jonchée de feuilles mortes, et les pluies l'avaient recouverte d'une hideuse couche de boue. Pourtant, il n'y avait pas de mauvais temps, quand il s'agit de chômer une de ces fêtes canadiennes aussi vieilles que la première croix plantée sur notre sol. Or, c'était la Sainte-Catherine, ce jour de réjouissances nationales; c'était la fête de cette sainte dont le nom seul apporte le sourire sur les lèvres des Canadiens. Terrebonne était alors, comme il l'est encore, essentiellement français, de sorte que tout ce qu'il y avait de gai s'était donné rendez-vous à la fourche des quatre chemins. La toilette était au grand complet; de beaux grands garçons à la tournure cavalière, et des jeunes filles charmantes (comme il y en a encore à Terrebonne).

Quand tout ce jeune monde fut disposé dans un local de vingt pieds carrés, c'était charmant à voir ; toutes ces têtes qui s'agitaient, ces pieds qui trépignaient, ces sourires, ces oeillades, ces petits mots jetés négligemment dans l'oreille d'une voisine en passant, tout cela formait le plus joli coup d'œil.

Après qu'on se fut donné force poignées de main, et peut-être quelques baisers, ... ce dont la chronique toujours discrète ne dit rien ; ... quand les

$32 \mathrm{http} / / / g r a n d q u e b e c . c o m / l e g e n d e s-d u-q u e b e c / c o n t e s-d u-q u e b e c /$ 


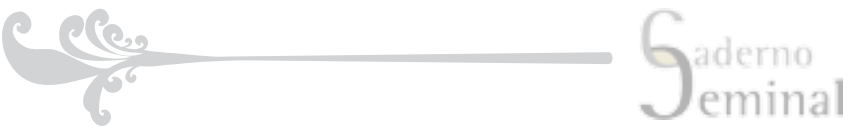

jeunes filles eurent bien babillé, et se furent débarrassées de leurs manteaux, quelque chose frappa d'abord tous les jeunes gens à leur en faire venir l'eau à la bouche: une forte odeur de sucre était répandue dans la maison. Dans un coin, il y avait une cheminée que réchauffait un bon feu ; sur ce feu, étaient disposées méthodiquement deux grandes poêles à frire, qui contenaient, ce que tout le monde a deviné, de la mélasse ; car que faire à la Sainte- Catherine, si l'on ne fait pas de la tire? La liqueur s'élevait à gros bouillons au-dessus des poêles, pour annoncer que tout serait bientôt prêt. Tous les yeux étincelèrent de joie. Après quelques minutes d'attente, employées à se prémunir contre les dangers qu'allait courir la toilette, le sucre fut apporté dans l'appartement. II n'y a pas besoin de dire que ce fut une fureur ; tout le monde se jetait dessus, en arrachait les morceaux des mains de ses voisins, avec des éclats de rire fous; tout l'appartement fut métamorphosé en une manufacture de tire. II y en avait partout, au plancher d'en haut comme à celui d'en bas ; l'appartement en était saturé. Puis, les lignes se formèrent, on joua à la seine avec de longues cordes de tire qui pêchaient les gens par le visage, chacun se permettait de dorer la figure de son voisin ; tout le monde était sucré, barbouillé, tatoué, de la façon la plus pittoresque. C'était un brouhaha dans la maison à ne plus entendre, un tintamarre à devenir sourd.

Une seule chose pouvait ralentir l'entrain et, pour un instant du moins, donner un peu de répit, c'était la musique, ce charme qui entraîne tous les êtres vivants, quelque grossiers que soient ses accords. Mais ici le roi des instruments venait de résonner. Un jeune blondin, à figure prétentieuse, assis dans un coin, promenait à tour de bras son archet sur son violon, en battant la mesure à grands coups de pied. Tout le monde se mit à fredonner et à sautiller : la tire était vaincue. Les souliers volent d'un bout à l'autre de la chambre sans qu'on les voit partir, les gilets en font autant : c'était un enchantement, un sort. Deux couples entrent en danse, et entament une gigue furieuse, chacun de leur côté. Les sauts, les gambades, les saluts, les demi-tours à droite et à gauche, c'était un vrai tourbillon, c'était comme la chanson: sens dessus dessous, sens devant derrière. À la gigue succédèrent la contredanse, la plongeuse, le triomphe, toutes danses animées, vives et gaies. Tout le monde était transporté. Danseurs et danseuses, hors d'eux-mêmes, sautaient, frottaient, piétinaient à en perdre la tête.

Au moment où la danse était le plus animée, on entend tout à coup frapper à la porte : ta, ta, ta.

- Ouvrez, dit un des danseurs.

Un monsieur, vêtu en noir des pieds jusqu'à la tête, à la figure belle et intéressante, à la tournure distinguée, entre dans la maison. Chacun des assistants, avec cette politesse hospitalière, caractère national des Canadiens, s'empresse autour du nouveau venu; mille politesses lui sont prodiguées, et on lui présente un siège 


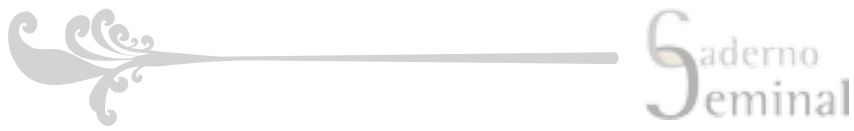

qu'il accepte. Les gens furent un peu surpris ; mais la politesse, I'hospitalité vraie et cordiale est si naturelle chez nos habitants, fait tellement partie de leurs mœurs, que l'étonnement fut de courte durée. La danse recommença comme de plus belle. L'étranger émerveillé regardait avec intérêt cette gaîté franche, si naïve, si expansive. Après quelques minutes, le monsieur étranger fut poliment invité à danser ; il ne se le fit pas répéter et accepta l'offre de la meilleure grâce du monde. Il choisit parmi les jeunes filles une des plus jolies, et la promena tambour battant dans tout l'appartement. Tout le monde admirait les grâces et la bonhomie de l'étranger, quand tout à coup la danseuse pousse un cri qui fait tressaillir tous les assistants et s'évanouit. La main de son partner avait violemment pressé la sienne. On la transporte dans une chambre, où les soins lui sont prodigués. La danse fut interrompue, tous les assistants commencèrent à regarder le monsieur avec soupçon. Le plaisir avait fait place à l'inquiétude. Un des jeunes gens s'avance vers l'étranger et lui demande son nom. Pas de réponse. Tout le monde se regarde avec étonnement : quel est cet homme singulier? La demande réitérée ne reçoit pas plus de réponse, même mutisme. L'étranger paraissait cloué à son siège, sans mouvement aucun ; seulement, ses yeux commençaient à devenir plus brillants. Les jeunes gens tinrent conseil, et on résolut de le faire sortir. L'un d'eux lui dit tranquillement : monsieur, nommezvous, ou sortez.- Pas de réponse. Les jeunes filles effrayées se retirèrent dans un coin de l'appartement, attendant avec anxiété le dénouement de cette scène extraordinaire. Nommez-vous, ou sortez, répéta un des jeunes gens. - Pas de réponse. Un silence morne régna pendant quelque secondes. Tous restaient indécis, presque terrifiés, en voyant cet homme impassible qui ne bougeait pas. Un des plus résolus dit aux autres : c'est la dernière fois, il faut qu'il sorte. Chacun hésite à s'approcher le premier. L'étranger ne bouge pas davantage ; seulement ses yeux deviennent de plus en plus brillants et lancent des éclairs; tous les assistants en sont éblouis; personne ne peut soutenir son regard de feu. - Sortez, sortez. - Pas de réponse. - - Eh bien! il faut le sortir, dit l'un d'entre eux. Plusieurs s'approchent de lui en même temps, et le saisissent, l'un par le bras, l'autre par le revers de son habit. Ils font un violent mais inutile effort ; il reste ferme et inébranlable sur sa chaise, comme une masse de plomb. Ses yeux deviennent plus ardents, toute sa figure s'enflamme graduellement ; en même temps une violente commotion se fait sentir, la maison tremble. - C'est le diable ! crie d'une voix perçante le joueur de violon, qui lance son instrument sur le parquet. C'est le diable ! c'est le diable ! répète tout le monde. Impossible de peindre la frayeur, le trouble, la confusion ; portes, châssis, tout vole en éclats sous les coups des fuyards; des cris déchirants se font entendre de tous côtés. II n'y a pas assez d'ouvertures pour recevoir à la fois tout ce monde qui se heurte, se presse, s'étouffe. Les lambeaux de gilets et de robes restent accrochés aux portes et aux châssis. Les blessures, les meurtrissures font pousser des gémissements. À droite, à gauche, les jeunes filles tombent évanouies. Les 
plus alertes fuient à toutes jambes, en criant partout : le diable ! le diable ! et réveillent tout le village avec ces lugubres mots. Tous les habitants se lèvent; on sort, on s'informe. Quand le fort de la terreur fut passé, que quelques-uns eurent recouvré leurs esprits, ils racontent ce qu'ils ont vu. - Allons trouver M. le curé, dit une voix ; - allons le trouver, répètent les autres.

Ils arrivent au presbytère, et trouvent le curé debout sur le seuil de sa porte, pâle, défait, ne sachant que penser. On lui raconte l'effrayant événement dans tous ses détails ; c'est le diable, lui dit-on, c'est le diable.

Quand le curé eut bien pris ses informations : - J'y vais aller, dit-il, attendezmoi un instant.

Le curé rentre dans son presbytère, se dirige vers sa bibliothèque, et y prend un petit livre à reliure rouge, le petit livre mystérieux, le Petit-Albert. II revient après quelques minutes, et tous se dirigent vers la maison, non sans trembler.

Le curé s'arrête à quelques pas, et fait signe à ses gens de ne plus avancer. Une clarté éblouissante était répandue dans la maison, on eût dit que l'incendie y exerçait ses ravages. Le curé regarde dans la maison, et aperçoit un homme de feu assis sur une chaise toujours à la même place, immobile. Surmontant la frayeur qui le gagnait malgré lui, il ouvre le Petit-Albert et en lit à haute voix quelques passages... I'homme de feu ne bouge pas. II recommence à lire, accompagnant sa lecture de signes mystérieux, l'homme de feu s'agite violemment sur son siège. Le curé lit encore quelques mots, puis il dit à haute et intelligible voix : Au nom du Christ sortez d'ici !

Tout à coup la maison reçoit une violente secousse, le sol tremble sous leurs pas. Un tourbillon de feu passa à travers un pignon de la maison. Tous s'enfuirent en poussant des cris effrayants.

Le diable était parti, emportant avec lui un des pans de la maison, que l'on n'a jamais pu retrouver. Le curé s'en retourna tranquillement à son presbytère, le Petit-Albert sous le bras.

(L’Avenir, février 1848) 